\title{
Pedro Almodóvar e Susan Sontag - Interseções Camp
}

\author{
Leandro Garcia Rodrigues*
}

\section{Resumo}

O presente artigo tem a finalidade de analisar, de forma interdisciplinar, as interseções teóricas entre o filme Tudo Sobre Minha Mãe, de Pedro Almodóvar, e o texto Notas Sobre o Camp, da crítica de cultura Susan Sontag. Nesta perspectiva, faremos uma abordagem analítica procurando perceber como essa "sensibilidade" - o Camp - pode ser percebida em algumas representações do referido filme de Almodóvar.

\section{Palavras-chave}

Cinema. Literatura. Cultura. Camp.

\section{Introdução}

Nos últimos anos, os debates acerca da chamada pós-modernidade têm se valido de inúmeras teorias e pressupostos que contribuem para criar um verdadeiro "emaranhado" teórico. O principal desafio ainda é estabelecer as reais (para alguns teóricos, algo ainda incógnito) fronteiras entre o Modernismo e o Pós-Modernismo, ou seja, ainda temos a antiga necessidade de evidenciar o estilo.

Todavia, já reside aí um "problema" desta pós-modernidade: nem sempre as fronteiras estão canonicamente definidas, são porosas, flexíveis e, em alguns casos, elas se valem mais de "sensibilidades" do que propriamente de teorias prontamente definidas - é o caso da noção de camp, proposta pela teórica e crítica norte-americana Susan Sontag.

Sontag, mais do que "definir" o que é o camp, levantou questões estéticas e ideológicas que possuem, ainda hoje, uma certa perenidade, uma vez que ainda se encontram atualizadas quanto à sua aplicabilidade. Certamente, não podemos deixar de ignorar o contexto do momento da escrita de Notas sobre o Camp - a década de 60 - palco histórico de mudanças comportamentais e de pensamento que até hoje nos relegam influências.

\footnotetext{
* Doutor e Pós-Doutor em Estudos Literários pela PUC-RJ. Professor e Diretor de Pesquisas do Colégio Naval (Marinha do Brasil).
} 
Por isso, propomos uma "interseção camp" entre as teorias de Susan Sontag e determinados aspectos do cinema de Pedro Almodóvar. O cineasta espanhol explora, em quase toda a sua filmografia, as possibilidades pelas quais as experiências marginalizadas podem ser, ao mesmo tempo, reveladoras e transgressoras dos mecanismos de poder naturalizados nas ideologias e nos modos de vida dominantes nas sociedades urbanas ocidentais contemporâneas, especialmente a espanhola - esta serve como paradigma de "tradicionalismos doentios" e necrosados que são "dissecados" e trazidos à lume para que seja exposta a sua natureza obsoleta e até inútil.

Quanto a Almodóvar, todas as nossas análises serão feitas tendo como foco principal o seu filme Tudo Sobre Minha Mãe. Este será o nosso alvo prioritário, não deixando de lado outras possíveis interseções com os seus demais filmes, especialmente no que concerne às temáticas abordadas.

Nossa proposta é justamente explorar esta estética da margem no sentido de localizar nela possíveis sintomas típicos do que chamamos de Pós-Modernismo. Como elucidação metodológica, é necessário esclarecer que outras teorias também serão utilizadas neste artigo, especialmente aquelas que tentam compreender ou mesmo problematizar a chamada pós-modernidade.

\section{Almodóvar - Uma Sensibilidade das Margens}

A ideia de Pós-Moderno é, em si, algo problematizador e passível de questionamentos sob vários pontos de vista. Estamos vivendo num período marcado pelo pluralismo ideológico que provoca uma constante mutação dos valores e das teses defendidas, ou seja, situamo-nos num sintomático "entre-lugar" epistemológico marcado pela diversidade de pensamentos e opiniões.

O debate sobre a contemporaneidade é assaz complexo e atravessado pelos mais diferentes fenômenos culturais - políticos, econômicos, sociais, comportamentais etc. Com isso, o debate sobre o pós-moderno se situa na esfera das transformações da cultura, principalmente no âmbito da pluralidade de (in)formação. A este respeito, Freferic Jameson afirmou:

As teorias do pós-moderno têm uma grande semelhança com todas aquelas generalizações sociológicas mais ambiciosas que, mais ou menos na mesma época, nos trazem as novidades a respeito da chegada e inauguração de um tipo de sociedade totalmente novo, cujo nome mais famoso é "sociedade pós-industrial" (Daniel Bell), mas que também é conhecida como sociedade de consumo, sociedade das mídias, sociedade de informação, sociedade eletrônica ou high tech e similares. (JAMESON, 1996, p. 29) 
A heterogeneidade é um dado característico e estilístico desses tempos atuais, trata-se de uma natureza caótica ${ }^{1}$ e culturalmente híbrida que se torna a base desta nova hermenêutica. A convivência dessas "várias sociedades" configuram o teor dos atuais estágios de debates a respeito do pós-modernismo, nos quais as várias possibilidades teóricas "transitam" e "chocam-se" umas às outras. Tal realidade levou Jameson a cunhar a idéia que de existe uma espécie de "dominante cultural":

[...] me parece essencial entender o pós-modernismo não como um estilo, mas como uma dominante cultural: uma concepção que dá margem à presença e à existência de uma série de características que, apesar de subordinadas umas às outras, são bem diferentes. (JAMESON, 1996, p. 29)

Essa "dominante cultural" seria um tipo de padronização cultural a partir de discursos dominantes. Entretanto, ainda que o pós-modernismo seja heterogêneo, determinadas dominantes culturais ainda são mantidas. O desafio é exatamente encontrar um sentido (um denominador comum) no interior deste hibridismo ideológico. É justamente no interior deste emaranhado de epistemologias que se situa a proposta estética da obra do cineasta espanhol Pedro Almodóvar.

\section{No Limiar do Desejo}

Muitas são as linhas de interpretação da obra Almodóvar, uma inegavelmente sempre se levanta como talvez a principal: o papel efusivo do desejo e suas múltiplas possibilidades de representação ao longo da sua filmografia. Podemos dizer que este sentimento se "materializa" e se "personifica" sob as mais variadas linguagens e sobre os mais diferentes objetos: são fantasias, sonhos, vontades recônditas, anseios desenfreados e busca de novas experiências que povoam as mentes e moldam o comportamento dos seus personagens. Neste afã, não podemos ignorar que um dos seus filmes venha a se chamar justamente $A$ Lei do Desejo (1986); Almodóvar explora e dá novos sentidos às leis universais que regem o desejo humano e a prática do mesmo, não é à toa que a principal fonte de intertextualidade de Tudo Sobre Minha Mãe é justamente a peça Um Bonde Chamado Desejo, de Tennessee Williams. A respeito deste assunto, ele declarou:

Há leis que se pode burlar, há outras que não. Por exemplo, qualquer um pode se atirar pela janela com o lícito desejo de voar. Aí intervém a Lei da Gravidade e por mais que se tente ignorá-la, numa questão de segundos o voador acabará chocando-se contra o solo. A lei do desejo é como a gravidade. Ainda que alguém a recuse, tem de the render tributo. E um tributo muito alto (CAÑIZAL, 1996, p. 51).

\footnotetext{
1 Dentro desta perspectiva do caótico, especialmente na tentativa de achar uma definição, o escritor norte-americano John Barth reclama no seu ensaio The Literature of the Replenishment que sua obra já ganhou várias classificações, dentre as quais existencialista, de humor negro, fabulista, fantástica, pré-modernista, modernista e, finalmente, pós-modernista. Ou seja, a experiência clara num certa indefinição classificatória
} 
Um fator importante a ser ressaltado diz respeito às condições histórico-sociais nas quais a obra de Almodóvar é criada e se estrutura - a sociedade espanhola. Ao longo de quatro décadas, a Espanha viveu sob a égide da ditadura de Francisco Franco. Esta foi caracterizada, dentre outros aspectos, pela repressão feroz ao comportamento e à prática desenfreada da censura como mecanismo de "controle" da moral desta sociedade. Foi através dos desejos sufocados, reprimidos e sublimados que sua obra cinematográfica tem sido construída. Com isso, o cineasta faz uma opção explícita por matizes historicamente marginalizados, como bem afirma Andreas Huyssen:

A meu ver, uma das principais diferenças entre o alto modernismo e a arte e a literatura que se lhe seguiram no anos 70 e 80 consiste, tanto na Europa quanto nos Estados Unidos, numa relação nova e criativa entre a grande arte e certas formas de cultura de massas. E é precisamente a recente auto-afirmação de culturas minoritárias e sua emergência na consciência pública que têm minado a crença modernista de que a alta cultura e as culturas inferiores devem permanecer rigorosamente separadas; essa rígida segregação simplesmente não faz sentido dentro de uma dada cultura minoritária que tenha sempre existido à sombra da alta cultura dominante. (HUYSSEN, 1991, p. 41)

Com o fim da ditadura franquista, em novembro de 1975, emerge uma Espanha sedenta por liberdade de expressão e que não consegue esquecer os "fantasmas" ditatoriais que insistem povoá-la e estabelecer uma presença como uma ferida incurável, marcada na própria carne das vítimas diretas e indiretas do regime. 0 cinema de Almodóvar é concomitante a esses "novos tempos" e dialoga com essa nova realidade: o que outrora fora abafado e perseguido, agora torna-se mecanismo de criação - é o desejo emergindo com uma força vital própria e marcado pelas rupturas marginalizadas: lesbianismo, homossexualidade masculina, bissexualismo, transexualismo, pedofilia, infidelidade conjugal, prostituição, AIDS etc; tudo (re)semantizado dentro de ambientes "underground" povoados pelas mais diferentes "tribos" - artistas plásticos em geral, escritores, poetas, cineastas e jovens exercendo as mais diferentes atividades - todos "carnavalizados" sob as dinâmicas destes novos tempos.

Os desejos reprimidos vêm à tona não somente na perspectiva das práticas sexuais libidinosas, mas também num livre consumo de drogas e bebidas alcoólicas. A cocaína e o álcool se tornam "veículos" de consumação desta nova liberdade reprimida em tempos de ditadura, especialmente quando se tem a fórmula "desejos = tóxico + sexo + rupturas". Novamente, Andreas Huyssen esclarece:

Foram especialmente as artes plásticas, a literatura, o cinema e a crítica produzidos por mulheres e artistas de minorias, com sua recuperação de tradições enterradas e mutiladas, sua ênfase na exploração, em produções ou experiências estéticas, de formas de subjetividade baseadas em gênero ou raça e sua recusa a ater-se a padrões canonizados que acrescentaram uma dimensão totalmente nova à crítica do alto modernismo e à emergência de formas alternativas de cultura. (HUYSSEN, 1991, p. 46). 
Ou seja, os tempos contemporâneos testemunharam um certo deslocamento do centro para as margens - a própria noção de cânon foi questionada e emergiram novas formas de representação e de pesquisa estética, daí a inevitável desintegração dos antigos dogmas modernistas, especialmente aqueles dos primeiros anos deste movimento.

Mas é na sexualidade que o cinema de Almodóvar encontra e expõe as suas "feridas" latejantes e sempre abertas às inflamações morais. Sob os tempos de Franco, a repressão sobre a cultura em geral e principalmente sobre o cinema ganhou proporções nunca vistas anteriormente na História da Espanha. Estavam proibidas alusões diretas ou indiretas à prostituição e a todas as chamadas "perversões sexuais" - adultério, aborto, relações sexuais ilícitas (pederastia e outras) e aquelas no âmbito da homossexualidade e as suas mais diferentes formas de vivência e representação, especialmente o travestismo.

Com a morte do ditador, um número considerável de filmes abordando a questão da sexualidade e do desejo foi produzido. Citando alguns exemplos: em 1975 Bardem produziu El Poder Del Deseo; em 1976 foi a vez de Picazo com Los Claros Motivos Del Deseo e mais tarde Buñuel produziu Esse Obscuro Objeto do Desejo; estes só para citar os principais exemplos cujos títulos fazem uso da palavra "desejo". É por isso que podemos falar de uma "explosão do desejo", este é colocado como elemento central do seu universo cinematográfico e, por isso mesmo, podemos fazer uma leitura da sociedade espanhola (e por que não do próprio Ocidente?) a partir deste critério; daí falarmos do desejo enquanto "metalinguagem" para compreensão da sua obra.

Em Tudo Sobre Minha Mãe, o desejo se torna uma interessante problemática, pois Almodóvar nos provoca ao colocar este sentimento como o limiar entre a vida e a morte, principalmente quando levamos em consideração a paixão de duas mulheres Manuela e Rosa - por um travesti, Lola. É bem clara a intenção do cineasta em reconfigurar totalmente os paradigmas da experiência de família cristã, e não é de forma inocente que aparece na tela a basílica da Sagrada Família, de Gaudi. É a partir desta referência que ele delineia o seu novo conceito de família, totalmente anárquico em relação ao modelo católico.

E o que será que atrai duas mulheres à outra mulher/homem que é Lola? Neste sentido, é sintomática uma declaração feita por Manuela: "Nós, mulheres, sempre fomos um pouco lésbicas". É a inversão total dos modelos sacramentados pela Tradição Cristã; por esta razão, o desejo é visto como uma postura totalmente revolucionária e vanguardista, mas que leva inclusive à morte de uma delas - a Irmã Rosa. Ao engravidar de Lola, ela não só contrai o vírus HIV como também desenvolve um problema de risco de parto devido à posição da sua placenta.

Mas já que as mulheres são "um pouco lésbicas" (na opinião da personagem Manuela), será essa dimensão masculina que as atraí à Lola, este que travestiu-se em mulher por vontade própria? Pois é a própria Manuela que afirma que Lola tinha "colocado seios maiores do que os dela"; anos mais tarde, ele/ela aparece à Irmã Rosa para ser tratado(a) na ONG na qual esta trabalhava e, mais uma vez, irradia a sua sedução e vitima a freira. 
Daí afirmarmos que a consumação do desejo, além de ser uma oportunidade de realização de sentimentos historicamente sublimados, também pode ser uma espécie de via de acesso à auto-destruição, como de fato aconteceu com Rosa e também com Manuela, pois esta última foi obrigada a fugir de Lola por não mais suportar viver em sua companhia.

Por essas razões, podemos interligar as intenções de Almodóvar à idéia de "fronteiras a serem conquistadas", na perspectiva teórica de Leslie Fiedler em seu ensaio Atravessar a Fronteira - Fechar a Lacuna: Pós-Modernismo. Para Fiedler, a cultura norte-americana tem especial atenção para a questão das fronteiras: no Western o Velho Oeste é sempre uma fronteira a ser conquistada, bem como no Imperialismo de dominação política exercido sobre países mais pobres. Outra fronteira é a conquista do próprio Espaço, simbolizado na série Star Wars - a galáxia colonizada. Assim como a estética do pornô, especialmente no que diz respeito às conquistas de novas práticas sexuais. Nesta perspectiva, podemos intertextualizar a obra de Pedro Almodóvar, não que ela seja classificada como "pornô", todavia sugere uma nova ordem das vivências sexuais - o desejo seria esta "nova fronteira" a ser definitivamente conquistada.

\title{
4. A sensibilidade Camp em Tudo sobre minha mãe
}

Muitas são as faces interpretativas de Tudo Sobre Minha Mãe; todavia, um aspecto causa um especial furor: o protagonismo de personagens transexuais. Neste caso, são dois: Agrado e Lola. Elas/eles desempenham importantes papéis na economia da trama contribuindo, de forma decisiva, para a resolução do enredo, principalmente Lola - pois tudo gira em torno da sua "paternidade transviada" ao engravidar Manuela e Rosa. Mas também Agrado, sem dúvidas um dos personagens mais ricos já criados por Almodóvar ao longo da sua carreira. Utilizaremos algumas das Notas sobre o Camp, propostas Susan Sontag, para tentar compreender as principais dinâmicas hermenêuticas deste filme. Sontag inicia suas Notas tentando esclarecer sua idéia acerca de Camp:

\begin{abstract}
Muitas coisas nesse mundo não têm nome; e muitas coisas, mesmo que tenham nome, nunca foram definidas. Uma delas é a sensibilidade - inequivocadamente moderna, uma forma de satisfação, mas não idêntica à satisfação - conhecida pela expressão esotérica Camp. (SONTAG, 1987, p. 318)
\end{abstract}

Inicialmente, as propostas de Susan Sontag parecem ser incompreensíveis, especialmente porque ela reluta na ideia de não querer "definir" o que é o Camp pois, ao seu entender, quando definimos já estamos "traindo" a finalidade do próprio termo, que é sugerir uma "nova sensibilidade", uma nova forma de entender o "sentir" e o "comportar-se". Sontag novamente insiste:

Sinto-me fortemente atraída pelo Camp e quase tão fortemente agredida. É por isso que quero falar a seu respeito e por isso posso fazê-lo. Pois ninguém que compartilhe sinceramente de uma determinada sensibilidade pode analisá-la; só pode, seja qual for a sua intenção mostrá-la. Para designar uma sensibilidade, traçar seus contornos e contar sua história exige-se uma profunda afinidade modificada pela repulsa. (SONTAG, 1987, p. 319) 
Ou seja, a sensibilidade deve ser "mostrada" e não "analisada". Tal noção faz sentido uma vez que não é possível analisar cartesianamente as realidades inerentes ao nosso subjetivo, isto é, nesse esforço de compreender um pouco mais do íntimo sensível, não cabe pressupostos puramente analíticos e herméticos - o Camp é justamente a abertura a novas possibilidades sensitivas, e não é sem intenção que Sontag dedica suas Notas a Oscar Wilde. Logo na primeira ela afirma:

1. Para começar de maneira bastante geral: Camp é um certo tipo de esteticismo. É uma maneira de ver o mundo como um fenômeno estético. Essa maneira, a maneira do Camp, não se refere à beleza, mas ao grau de artifício, de estilização.

2. Enfatizar o estilo é menosprezar o conteúdo, ou introduzir uma atitude neutra em relação ao conteúdo. Não é preciso dizer que a sensibilidade Camp é descompromissada e despolitizada - pelo menos apolítica. (SONTAG, op. cit. p. 320)

Tais afirmações são elucidativas: quando Sontag afirma que "Camp é um certo tipo de esteticismo" ela já antevê o Camp como uma realidade estética, ou seja, artística - por isso mesmo justificando seu desejo inicial de não definir, uma vez que a arte perde bastante da sua natureza quando se tenta decodificá-la tecnicamente. Daí que, além da questão estética, há também aquela de ordem estilística, tudo confrontando para a dimensão artística do Camp. Outro aspecto importante diz respeito ao fato de esta nova sensibilidade ser apolítica; neste sentido, cabe interligar o cinema de Pedro Almodóvar.

O cineasta já afirmou várias vezes que sua obra não possui pretensões políticas no sentido de ser um cinema politicamente engajado, Almodóvar opta por não fazer dessas temáticas o mote principal dos seus filmes. É ele mesmo quem afirma: Eu nunca falo de Franco; eu simplesmente ignoro a sua existência. Eu começo
depois de Franco. As histórias acontecem como se ele nunca tivesse existido. [...]
Os personagens nos meus filmes são apolíticos. O prazer deve ser obtido
imediatamente, hedonísticamente, eis a razão principal das suas vidas (apud
VERNON, 2003, p. 28).

Almodóvar opta em não incluir aspectos temáticos da recente história da Espanha, especialmente no que concerne à experiência da ditadura franquista que tanto violentou os direitos humanos e fez da censura uma da suas principais práticas de controle estético-ideológico. Em relação a esta opção pela não inclusão de questionamentos políticos, Andreas Huyssen tem uma interessante opinião:

O que havia de novo nos anos 70 era, de um lado, a emergência de uma cultura de ecletismo, um pós-modernismo amplamente afirmativo que abandonara qualquer reivindicação de crítica, transgressão ou negação; e, por outro lado, um pósmodernismo alternativo em que resistência, crítica e negação do status quo foram redefinidas em termos não-vanguardistas e não-modernistas, que se adequavam mais efetivamente aos avanços políticos da cultura contemporânea do que as antigas teorias do modernismo. (HUYSSEN, 1991, p. 31) 
Com tal afirmação, Huyssen deixa claro que o Modernismo histórico possuía esta característica de interligar vida e arte, utilizando a obra de arte como possibilidade de crítica das instituições e práticas sociais vigentes, daí a tese de que o artista possuía uma certa responsabilidade social, no sentido de que sua produção artística ajudaria um pouco na desalienação da sociedade. Tal obrigação, para Andreas Huyssen, não cai nos ombros do artista pós-moderno, já que este para criar não tem a necessidade de fazer de sua obra um farol a iluminar as trevas da alienação geral. Daí a inclusão de Pedro Almodóvar e sua obra dentro de uma categoria pós-moderna de artista - ele assume tais prerrogativas estilísticas. Seu objetivo maior é dar voz aos elementos historicamente excluídos do discurso artístico oficial, como bem define Kathleen Vernon:

Os filmes de Almodóvar possuem uma forma curiosa de registrar a marginalização. Ele nunca limita seus filmes a um único protagonista, opta pelo homossexual, pelo bissexual, transexual, drogados, punks - personagens que recusam serem segregados em subculturas isoladas, pois eles "se sentem" parte de uma "nova mentalidade" (VERNON, 2003, p. 34).

Tal projeto artístico fica bem claro no filme Tudo Sobre Minha Mãe, no qual Almodóvar faz opção por protagonistas transexuais ${ }^{2}$ - Lola e Agrado. É intrigante a relação (ou sedução) de Lola em relação às duas mulheres que ele/ela engravidou. Natural da Argentina, decide morar na Espanha e é lá que conhece Manuela durante as encenações da peça Um Bonde Chamado Desejo, daí o fato de este texto ter marcado profundamente a mãe de Esteban ${ }^{3}$ e retornar às suas lembranças como testemunha de situações já vividas. Quando vivem em Barcelona, o primeiro Esteban vai a Paris e retorna "transformada" em Lola. Manuela narra a sua própria história à Rosa escondendo-se por trás de uma suposta amiga, a quem tudo acontecera: "Lola tem o pior de uma mulher e o pior de um homem. Fora o par de peitos, ele não havia mudado tanto, terminei aceitando-o. Nós mulheres fazemos de tudo para não ficarmos sozinhas".

E continua o seu monólogo recordando de forma trágica a sua experiência com Lola:

Nós somos idiotas e um pouco lésbicas. Ele [Lola] passava o dia com um biquini mínimo, transando com tudo o que aparecia e fazia um escândalo se eu usasse um biquini ou minisaia. Como pode ser machista com aquele par de peitos?

É perturbador o fascínio sedutor que Lola exerce sobre algumas mulheres, porém o mais sintomático é o desejo destas em entregar-se sexualmente a um travesti. Alguns psicanalistas defendem a tese de que as mulheres (neste filme, especialmente a freira) que cometem tal prática sexual o fazem por quererem se entregar a uma outra mulher. A possessão sexual acontece pelo duplo masculino/feminino, é uma mulher (pelo menos na aparência física) que penetra

\footnotetext{
${ }^{2}$ A opção de Almodóvar por personagens travestis é algo sintomático, em vários dos seus filmes eles surgem com muita força expressiva, ajudam a decidir o próprio enredo. Outra questão interessante é que eles são sempre apresentados como mulheres, inclusive os pronomes pessoais são todos flexionados no feminino.

${ }^{3}$ Fruto da união entre Manuela e Lola, também chamado Esteban.
} 
falicamente o corpo de uma outra, isto é, não se trata de uma relação homossexual no sentido de ambos serem do mesmo sexo, é justamente o entre-lugar da experiência sexual que seduz muitas mulheres que praticam uma relação sexual com um travesti. Há também uma outra via de especulação analítica: algumas negam a possibilidade de entregar-se sexualmente a um homem com todo o seu arcabouço de masculinidade constituído porém, paradoxalmente, sentem a necessidade de "completar" o ato sexual, daí a necessidade de um falo para "consumar" a relação biológico e fisicamente esperada.

Mas todas essas questões e hipóteses não são apresentadas no filme, são especulações da Ciência para tentar entender este desejo complexo e intrigante. Mas é exatamente este fato que aproxima Manuela de Rosa e reaproxima Lola delas. Ao saber da verdade, Manuela vocifera contra a freira já sua amiga: "Mas como pode ter transado com Lola?" É a pergunta feita em meio a gritos e a um profundo sentimento de que o "mal" voltou a repetir-se. Lola atacou ainda mais: contaminou Rosa com o vírus HIV e fugiu para a Argentina com o dinheiro e outros bens roubados de Agrado. Ele/ela também faz a sua "viagem de retorno" às origens, todavia sua catábase ${ }^{4}$ não se mostrou tão problemática e reveladora quanto a de Manuela, pelo menos como foi mostrado no filme.

Lola se revela fisicamente no enterro de Rosa, esta faleceu devido a complicações na hora do parto. $\mathrm{O}$ aparecimento tem um ar de espetáculo. Lola surge impecavelmente vestida de preto, muito elegante e com uma postura que lembra as representações vampirescas do cinema: de bengala, óculos escuros, reservada(o) e um pouco distante. A conversa com Manuela é dura e tensa, marcada pela emoção de ambas as partes:

LOLA: Manuela, fico feliz de ver você. É uma pena que seja aqui.

MANUELA: Não poderia ser em outro lugar. Você não é um ser humano Lola, você é uma epidemia.

LOLA: Sempre fui excessiva e estou muito cansada. Manuela estou morrendo, venha. Estou me despedindo de tudo. Roubei Agrado para pagar a viagem à Argentina, queria ver a nossa cidade pela última vez, o rio, nossa rua... E fico feliz de também poder me despedir de você. Só me falta conhecer o filho da irmã Rosa, o meu filho. Sempre sonhei em ter um filho, você sabe disso.

MANUELA: Quando parti de Barcelona estava grávida de você.

LOLA: O quê? Quer dizer que você também... Você o teve?

MANUELA: Um garoto maravilhoso.

LOLA: Eu quero vê-lo. Você o trouxe com você?

MANUELA: Está em Madrid, mas não pode vê-lo.

LOLA: Mesmo que seja de longe. Prometo que ele não me verá, é a última coisa que te peço.

MANUELA: Não pode vê-lo.

LOLA: Manuela, por favor.

MANUELA: Há seis meses um carro o atropelou e o matou, eu vim a Barcelona só para contar a você, eu lamento, lamento.

\footnotetext{
${ }^{4}$ A respeito desse tipo de "retorno", Carlinda Nuñes esclarece: "Como em toda catábase mítica (Orfeu, Ulisses, Enéias, Dante... são os mais famosos visitantes das Sombras), o viajante enfrenta provas, reviravoltas e reconhecimentos. O destino interfere como adjuvante, no encaixamento de histórias que se completam para a obtenção da verdade final" (NUÑES, 2003, p. 193).
} 
Após este relato, Lola chora compulsivamente sentada(o) no chão do cemitério. Neste momento, demonstra uma profunda sinceridade quando sabe da morte do filho que não conhecera, é também um momento de forte catarse, pois nos solidarizamos com o personagem já fraco e combalido pela AIDS. É quando a força da presença de Lola se transfigura na sua demonstrada fraqueza diante das vicissitudes da vida. E Manuela é rígida na sua avaliação: "Você não é um ser humano Lola, você é uma epidemia". Certamente, a revolta que a fez fugir do marido travestido de outrora agora é reforçada pela dor da perda de Rosa, sua amiga nos últimos meses. É quando Lola se torna metáfora de doença, contaminação, perigo - ou seja - o que ela toca, destrói.

A última aparição de Lola acontece um mês após o falecimento de Rosa, Manuela leva o pequeno Esteban ${ }^{5}$ para que o pai o conheça. Sua decisão de batizá-lo com o mesmo nome do seu filho é questionador: será que este terceiro Esteban "daria certo"? Pois o primeiro da linhagem é associado a uma epidemia e o segundo foi atropelado. Seguramente, a iniciativa de Manuela simboliza a sua esperança neste novo filho e o desejo ardente de o mesmo recuperar as suas razões para continuar vivendo.

A cena em que Lola segura o filho no seu colo é intrigante: uma aparente reconfiguração da cena da Pietá, quando Maria segura Cristo já morto sobre o seu ventre. Mas Esteban representa um sopro de vida em meio à morte, mesmo que esta não seja a opinião do seu pai: "Meu filho, lamento deixar uma herança tão ruim". Lola referia-se à AIDS, a única coisa que pode legar a Esteban, uma herança de morte, a continuação da sua semente destrutiva, a sua epidemia. Logo Manuela a(o) convence que não há razões para se desesperar, pois a criança não está desenvolvendo o vírus.

Esta cena é bela na sua imagética: duas mulheres e dois filhos - um bebê e outro presente através da fotografia e do seu diário, os dois Esteban interligados por Lola - pai cuja imagem se parece com uma mãe, a ponto de a avó do pequeno bebê (também chamada Rosa) não identificar que se trata de um travesti e pensa que é uma amiga de Manuela. Está bem clara a intenção de Almodóvar: reconfigurar totalmente a noção tradicional de família cristã representada por Maria, José e Jesus. Pela imagem, são duas mulheres mãe/pai segurando um pequeno filho.

Lola é, acima de tudo, intrigante e enigmática. Sua presença física no filme é rápida mas o seu efeito é catastrófico, presentifica-se em toda a obra como uma imagem, uma sombra, uma lembrança paradoxal com força destrutiva e coesiva: ela/ele uniu Manuela a Esteban (seu filho morto) e à Rosa, mas também separa esta última através do parto e volta a unir quando o seu último filho é entregue à Manuela para que esta o criasse. Mas como toda epidemia, sua presença maior é através das marcas que deixa registradas em todos que com ele/ela conviveram.

Susan Sontag defende a tese de que este tipo de personagem possui uma espécie de "força" no seu íntimo constitutivo, por isso ele é sempre apresentado como um bom exemplo de sensibilidade Camp:

\footnotetext{
${ }^{5}$ Fruto de sua relação com a freira Rosa. Manuela batiza o bebê com o mesmo nome do seu único filho morto em um acidente - Esteban.
} 
9. Como gosto pessoal, o Camp responde em particular ao marcadamente atenuado e ao fortemente exagerado. $O$ andrógino é seguramente uma das grandes imagens da sensibilidade Camp. [...] Aliado ao gosto Camp pelo andrógino existe algo que parece bastante diferente mas não é: uma tendência ao exagero das características sexuais e aos maneirismos da personalidade. Por razões óbvias, os melhores exemplos que podemos citar são as estrelas de cinema. (SONTAG, 1987, p. 322323)

O andrógino (o travesti, na perspectiva deste filme) se configura como este elemento desintegrador das antigas noções de gênero: o masculino e o feminino não conseguem responder à emergência dessas novas dinâmicas ideológicocomportamentais, daí a necessidade de se criar um "terceiro gênero" - este andrógino, na idéia de Sontag. É o papel exercido pelo travesti Lola: as mulheres se sentem seduzidas por ele por vários fatores, dentre os quais, um certo esvaziamento da própria noção da masculinidade histórica - busca-se uma nova configuração não somente na ordem do comportamento, mas também do físico. Outro aspecto abordado por Susan Sontag diz respeito aos exageros que configuram a criação desses personagens e respectivos trejeitos; sobre essa questão específica, temos uma outra nota:

5. O gosto Camp tem afinidades com certas artes mais que com outras. Vestuário, mobília, todos os elementos de decoração visual, por exemplo, constituem grande parte do Camp. Pois a arte Camp freqüentemente é uma arte decorativa que enfatiza a textura, a superfície sensual e o estilo em detrimento do conteúdo.

8. Camp é uma visão do mundo em termos de estilo - mas um estilo peculiar. É a predileção pelo exagerado ${ }^{6}$, por aquilo que está "fora", por coisas que são o que não são. (SONTAG, 1987, p. 321-322)

No universo do transexualismo, a hipérbole se torna um dado fundamental na composição estética dos elementos nele inseridos: roupas, acessórios, bijuterias, maquiagem, tinturas, (re)criação de voz e uma preocupação exagerada com a aparência física - o corpo se torna o principal desafio para a definitiva adaptação neste sistema.

No filme Tudo Sobre Minha Mãe, o outro travesti que "rouba a cena" se chama Agrado. Amigo íntimo e antigo de Manuela, conhece esta desde o tempo em que estava casada com o primeiro Esteban (futuro Lola). Quando da separação de Manuela, Agrado foi fiel à amiga, porém com o desaparecimento de Manuela nunca mais se viram, até o momento que a mesma retorna à cidade onde tudo começou para tentar reconquistar um sentido para a sua vida. Neste filme, é interessante notar que Agrado só surge enquanto sujeito quando apresenta e explicita o seu corpo e as transformações feitas no mesmo ao longo de inúmeras intervenções estéticas. A começar na cena quando está vestido(a) com um Chanel a andar pelas ruas com Manuela - percebe-se claramente o seu nível de satisfação e realização:

\footnotetext{
${ }^{6}$ Neste afã de optar pelo exagero, a obra de Almodóvar também recebe uma outra classificação a de Kitsch. É explícita a utilização de aspectos decorativos nos cenários dos filmes: cores muito fortes (especialmente o vermelho), luzes sempre brilhando fortemente, exageros de detalhismos decorativos, especialmente nas mobílias dos ambientes e nas roupas usadas pelos personagens.
} 
MANUELA: Você está ótima.

AGRADO: Nada como um bom Chanel para se sentir respeitável.

MANUELA: E é verdadeiro?

AGRADO: A única coisa verdadeira que tenho são os meus sentimentos e os litros de silicone que pesam horrores.

No caso de Agrado e de outros transformistas, a fala sobre si mesma(o) é necessariamente uma fala sobre sua experiência corporificada, é a partir do corpo que inicia a sua interação no meio onde convive. É sintomático o monólogo do travesti no momento em que as duas atrizes (Huma e Nina) comunicam que não comparecerão ao teatro naquela noite:

Cancelaram o espetáculo. Aos que quiserem será devolvido o ingresso, mas aos que não tiverem o que fazer e já estando no teatro, é uma pena saírem. Se ficarem, eu irei diverti-los com a história de minha vida. Adeus, sinto muito [aos que estão saindo]. Se ficarem aborrecidos, ronquem, assim RRRRR. Entenderei, sem ter meus sentimentos feridos. Sinceramente. Me chamam Agrado, porque toda a minha vida sempre tento agradar aos outros. Além de agradável, sou muito autêntica. Vejam que corpo feito à perfeição. Olhos amendoados: 80 mil. Nariz: 200 mil. Um desperdício, porque numa briga fiquei assim [mostra o desvio no nariz]. Sei que me dá personalidade, mas, se tivesse sabido, não teria mexido em nada. Continuando. Seios: dois, porque não sou nenhum monstro. Setenta mil cada, mas já estão amortizados. Silicone... Onde? [Grita um homem da platéia]. Lábios, testa, nas maçãs do rosto, quadris e bunda. O litro custa 100 mil. Calculem vocês, pois eu já perdi a conta. Redução de mandíbula, 75 mil. Depilação completa a laser, porque a mulher também veio do macaco tanto ou mais que o homem, sessenta mil por sessão. Depende dos pêlos de cada um. Em geral duas a quatro sessões. Mas se você for uma diva flamenga, vai precisar de mais. Como eu estava dizendo, custa muito ser autêntica e, nessas coisas, não se deve economizar, porque se é mais autêntica quanto mais se parece com o que sonhou para si mesma.

O mais importante de ser notado é que Agrado não busca o ocultamento do seu corpo - explicita-o a todos e faz dele um verdadeiro espetáculo: seu corpo está no lugar da peça que não foi apresentada e recebe a anuência do diretor e do ator principal que ficam a observar a sua performance à distância, saudando e batendo palmas no final da fala numa atitude de concordância com o que foi exposto. Outra questão relevante é a exibição de um corpo integralmente fabricado - inclusive atribuindo valores pecuniários usados durante o processo de transformação de cada parte; há um desejo expresso de evidenciar este corpo formatado e transformá-lo em objeto de exibição.

A individualização do sujeito travesti, expressa na fala de Agrado, acontece no sentido de realização de um desejo próprio e da inscrição desse desejo em um corpo a transfiguração desse desejo em corporalidade. A vontade do travesti é o de tornarse outro (sempre uma mulher) e Agrado assinala em seu discurso o processo que levou ao produto final da mudança. Ao dizer que o que tem de mais autêntico é o silicone, ele/ela revela que o autêntico em seu corpo é justamente produto de sua criação, da intervenção do seu desejo. 
Agrado "se sabe" travesti, é a sua natureza constituída através das transformações operadas no seu corpo moldado como linguagem onde a "escrita" foi feita pelo silicone injetado, daí decorre o fato de que sua história de vida é narrada através desta linguagem, desta narratividade inscrita através do seu corpo-texto que é desejo e objeto ao mesmo tempo: é o lócus interventivo de metamorfose física que provoca o desejo e o interesse de outros.

Não resta a menor dúvida de que há, na personagem Agrado, muito do que Sontag defende como "exagero" que ajuda a constituir o Camp. Todavia, não se trata de um uso puramente hiperbólico no sentido genuíno de hipérbole. Trata-se, antes de qualquer coisa, de um exagero estilístico, necessário para a configuração dessas novas linguagens a que a pós-modernidade se propõe a explorar. Tanto Agrado como Lola têm consciência de que "a predileção pelo exagerado, por aquilo que está 'fora"" (nota 8) é importante para a confirmação delas no seu meio - ou transfiguram o corpo outrora masculino ou não conseguem um espaço dentro do universo travestido ao qual adentram. É uma espécie de encenação, como bem atesta Sontag em outra nota: "[...] Perceber o Camp em objetos e pessoas é entender que Ser é Representar um papel. É a maior extensão, em termos de sensibilidade, da metáfora da vida como teatro." (fragmento da Nota 10).

Ou seja, nesta perspectiva de vida, há uma inevitável necessidade de ficcionalizar a própria existência, ficcionalizar a personalidade e o próprio corpo e suas respectivas práticas. Daí que Ser é representar um papel: Esteban se torna Lola e um antigo caminhoneiro se torna Agrado. Por isso a defesa inicial de Susan Sontag de que o Camp é uma sensibilidade e não uma nova definição de valores. De fato, somente na esfera das sensibilidades que podemos discutir e tentar compreender essas diversas mutações das ideologias e dos comportamentos. Somente se estivermos numa esfera Camp.

\section{Conclusão}

Interligar criticamente Pedro Almodóvar e Susan Sontag pode parecer uma tarefa árdua e de difícil realização. Contudo, com um olhar analiticamente atento, podemos perceber que tal diálogo é possível e salutar - necessário para tentarmos compreender um pouco a complexidade teórica na qual estamos inseridos na contemporaneidade.

Pedro Almodóvar é aquele que em outras épocas fora descriminado e considerado um "lunático", um "visionário", e agora se tornou cult e inclusive se transformou em personalidade fácil de ser encontrada nos grandes circuitos internacionais de cinema. O próprio filme Tudo Sobre Minha Mãe foi laureado com o Oscar de Melhor Filme Estrangeiro no ano de sua estréia. Mas o que representa Almodóvar enquanto um vanguardista? É sem dúvida um autor de grande inventividade e sensibilidade, dono de um humor ímpar e uma capacidade de criticar lírico ou comicamente.

Mas a sua dimensão marcadamente de vanguarda lhe permite transitar por discussões nem sempre bem vistas por aqueles setores ainda retrógrados da 
sociedade ocidental, que têm a espanhola como a sua metonímia. Ao expor e debater temas como travestismo, homossexualismos masculino e feminino, dependência química e a tradicional "dor de viver", Almodóvar quer explicitamente nos orientar para um outro espaço do debate: a necessidade desesperada de transgredir modelos ultrapassados e canonizados como historicamente "normais", daí a sua nova versão de família proposta no filme, daí as suas diversas "propostas de feminino", a começar pela figura do travesti. Agrado e Lola representam uma sexualidade desviada daquilo que se concebe como "normal" num Ocidente reacionário e conservador. Contudo, esses personagens se mostram "bem resolvidos" quanto às suas vidas e, principalmente, com as transformações físico-existenciais às quais se submeteram. $\mathrm{Na}$ verdade, são seus corpos os verdadeiros "rebeldes" a exalarem rupturas e "quebras" de diversos valores e tabus.

O que concluir sobre Susan Sontag? Enquanto crítica de cultura, Sontag sempre esteve no seio de debates de assuntos intrigantes, a começar pelo seu próprio gesto de assumir publicamente a sua homossexualidade. Quando escreveu Notas Sobre $o$ Camp certamente não tinha ideia do vigor das suas propostas crítico-teóricas; negativamente criticada por alguns setores acadêmicos, suas teorias sobre o Camp aos poucos provaram uma verdade: que são atuais apesar do contexto histórico, ou seja, são perenes e ganham novas semânticas mediante o momento no qual são analisadas. Justamente esta é a grande "novidade" trazida pelas Notas sobre o Camp: a noção de Camp reside na clave das sensibilidades, impossibilitando uma abordagem unicamente no âmbito das terminologias, como geralmente se costuma fazer. Camp não se mostra como mais um termo a circular no universo acadêmico, já tão povoado de tal realidade; torna-se, desta forma, uma oportunidade de questionarmos a validade de determinados termos já tão massificados pelo jargão crítico e desprovidos de qualquer tipo de sensibilidade.

É nesta perspectiva que interligamos alguns aspectos da obra de Pedro Almodóvar às teorias sobre o Camp de Susan Sontag. Só conseguimos compreender melhor os objetivos temático-estilísticos do cineasta espanhol na ordem das sensibilidades, especialmente a exploração daquelas historicamente excluídas do discurso cultural dito "oficial". É fazer dos discursos "de margem" um espaço e uma oportunidade privilegiados para questionarmos a validade de determinadas opiniões. Enfim, um espaço para o necessário questionamento do próprio Cânone.

Plusieurs fois vint un Camarade, le même, cet autre, me confier le besoin d'agir: que visait-il - comme la démarche à mon endroit annonça de sa part, aussi, à lui jeune, l'occupation de créer, qui paraît suprême et réussir avec des mots; j'insiste, qu'entendait-il expressément ?

Se détendre les poings, en rupture de songe sédentaire, pour un trépignant vis-àvis avec l'idée, ainsi qu'une envie prend ou bouger: mais la génération semble peu agitée, outre le désintéressement politique, du souci d'extravaguer du corps. Excepté la monotonie, certes, d'enrouler, entre les jarrets, sur la chaussée, selon l'instrument en faveur, la fiction d'un éblouissant rail continu.

Agir, sans ceci et pour qui n'en fait commencer l'exercice à fumer, signifia, visiteur, je te comprends, philosophiquement, produire sur beaucoup un mouvement qui te donne en retour l'émoi que tu en fus le principe, donc existes: dont aucun ne se croit, au préalable, sûr. Cette pratique entend deux façons; ou, par une volonté, à I'insu, qui dure une vie, jusqu'à l'éclat multiple - penser, cela: sinon, les déversoirs 
à portée maintenant dans une prévoyance, journaux et leur tourbillon, y déterminer une force en un sens, quelconque de divers contrariée, avec l'immunité du résultat nul.

Au gré, selon la disposition, plénitude, hâte.

Ton acte toujours s'applique à du papier; car méditer, sans traces, devient évanescent, ni que s'exalte l'instinct en quelque geste véhément et perdu que tu cherchas.

Écrire -

L'encrier, cristal comme une conscience, avec sa goutte, au fond, de ténèbres relative à ce que quelque chose soit: puis, écarte la lampe.

Tu remarquas, on n'écrit pas, lumineusement, sur champ obscur, l'alphabet des astres, seul, ainsi s'indique, ébauché ou interrompu; l'homme poursuit noir sur blanc.

Ce pli de sombre dentelle, qui retient l'infini, tissé par mille, chacun selon le fil ou prolongement ignoré son secret, assemble des entrelacs distants où dort un luxe à inventorier, stryge, nœud, feuillages et présenter.

Avec le rien de mystère, indispensable, qui demeure, exprimé, quelque peu.

Je ne sais pas si l'Hôte perspicacement circonscrit son domaine d'effort: ce me plaira de le marquer, aussi certaines conditions. Le droit à rien accomplir d'exceptionnel ou manquant aux agissements vulgaires, se paie, chez quiconque, de l'omission de lui et on dirait de sa mort comme un tel. Exploits, il les commet dans le rêve, pour ne gêner personne; mais encore, le programme en reste-t-il affiché à ceux qui n'ont cure.

L'écrivain, de ses maux, dragons qu'il a choyés, ou d'une allégresse, doit s'instituer, au texte, le spirituel histrion.

Plancher, lustre, obnubilation des tissus et liquéfaction de miroirs, en l'ordre réel, jusqu'aux bonds excessifs de notre forme gazée autour d'un arrêt, sur pied, de la virile stature, un Lieu se présente, scène, majoration devant tous du spectacle de Soi; là, en raison des intermédiaires de la lumière, de la chair et des rires le sacrifice qu'y fait, relativement à sa personnalité, l'inspirateur, aboutit complet ou c'est, dans une résurrection étrangère, fini de celui-ci: de qui le verbe répercuté et vain désormais s'exhale par la chimère orchestrale.

Une salle, il se célèbre, anonyme, dans le héros.

Tout, comme fonctionnement de fêtes: un peuple témoigne de sa transfiguration en vérité.

Honneur.

Cherchez, où c'est, quelque chose de pareil -

Le reconnaîtra-t-on dans ces immeubles suspects se détachant, par une surcharge en le banal, du commun alignement, avec prétention à synthétiser les faits divers d'un quartier; ou, si quelque fronton, d'après le goût divinatoire français, isole, sur une place, son spectre, je salue. Indifférent à ce qui, ici et là, se débite comme le long de tuyaux, la flamme aux langues réduites.

Ainsi l'Action, en le mode convenu, littéraire, ne transgresse pas le Théâtre; s'y limite, à la représentation - immédiat évanouissement de l'écrit. Finisse, dans la rue, autre part, cela, le masque choit, je n'ai pas à faire au poëte: parjure ton vers, il n'est doué que de faible pouvoir dehors, tu préféras alimenter le reliquat d'intrigues commises à l'individu. À quoi sert de te préciser, enfant le sachant, comme moi, qui n'en conservai notion que par une qualité ou un défaut d'enfance exclusifs, ce point, que tout, véhicule ou placement, maintenant offert à l'idéal, y est contraire - presque une spéculation, sur ta pudeur, pour ton silence - ou défectueux, pas direct et légitime dans le sens que tout à l'heure voulut un élan et vicié. Comme jamais malaise ne suffit, j'éclairerai, assurément, de digressions prochaines en le nombre qu'il faudra, cette réciproque contamination de l'œuvre et des moyens: mais auparavant ne convint-il spacieusement de s'exprimer, ainsi que d'un cigare, par jeux circonvolutoires, dont le vague, à tout le moins, se traçât sur le jour électrique et cru?

Un délicat $a$, je l'espère, pâti -

Extérieurement, comme le cri de l'étendue, le voyageur perçoit la détresse du sifflet. «Sans doute» il se convainc: «on traverse un tunnel - l'époque - celui, long le dernier, rampant sous la cité avant la gare toute puissante du virginal palais 
central, qui couronne.» Le souterrain durera, ô impatient, ton recueillement à préparer l'édifice de haut verre essuyé d'un vol de la Justice.

Le suicide ou abstention, ne rien faire, pourquoi? - Unique fois au monde, parce qu'en raison d'un événement toujours que j'expliquerai, il n'est pas de Présent, non - un présent n'existe pas... Faute que se déclare la Foule, faute - de tout. Mal informé celui qui se crierait son propre contemporain, désertant, usurpant, avec impudence égale, quand du passé cessa et que tarde un futur ou que les deux se remêlent perplexement en vue de masquer l'écart. Hors des premierParis chargés de divulguer une foi en le quotidien néant et inexperts si le fléau mesure sa période à un fragment, important ou pas, de siècle.

Aussi garde-toi et sois là.

La poésie, sacre; qui essaie, en de chastes crises isolément, pendant l'autre gestation en train.

Publie.

Le Livre, où vit l'esprit satisfait, en cas de malentendu, un obligé par quelque pureté d'ébat à secouer le gros du moment. Impersonnifié, le volume, autant qu'on s'en sépare comme auteur, ne réclame approche de lecteur. Tel, sache, entre les accessoires humains, il a lieu tout seul: fait, étant. Le sens enseveli se meut et dispose, en chœur, des feuillets.

Loin, la superbe de mettre en interdit, même quant aux fastes, l'instant: on constate qu'un hasard y dénie les matériaux de confrontation à quelques rêves; ou aide une attitude spéciale.

Toi, Ami, qu'il ne faut frustrer d'années à cause que parallèles au sourd labeur général, le cas est étrange: je te demande, sans jugement, par manque de considérants soudains, que tu traites mon indication comme une folie je ne le défends, rare. Cependant la tempère déjà cette sagesse, ou discernement, s'il ne vaut pas mieux - que de risquer sur un état à tout le moins incomplet environnant, certaines conclusions d'art extrêmes qui peuvent éclater, diamantairement, dans ce temps à jamais, en l'intégrité du Livre - les jouer, mais et par un triomphal renversement, avec l'injonction tacite que rien, pal pitant en le flanc inscient de I'heure, aux pages montré, clair, évident, ne la trouve prête; encore que n'en soit peut-être une autre où ce doive illuminer.

\section{Referências}

ALLINSON, Mark. A Spanish Labyrinth - The Films of Pedro Almodóvar. London: I.B. Tauris Publischers, 2001.

BARTH, John. The Literature of Exaustion. In: The Friday Book. Baltimore:

John Hopkins UP, 1984, p. 62-76.

The Literature of Replenishment. In: The Friday Book. Baltimore:

John Hopkins UP, 1984, p. 193-206.

CAÑIZAL, Eduardo Peñuela (org.). Urdidura de Sigilos - Ensaios sobre o Cinema de Almodóvar. São Paulo: AnnaBlume \& ECA -USP, 1996.

FIEDLER, Leslie. Cross the Border - Close the Gap: Postmodernism. In: PÜTZ, Manfred \& FREESE, Peter (eds.). Postmodernism in American Literature. Darmstadt: Thesen, 1984 , p. $151-166$.

HUTCHEON, Linda. Moldando o Pós-Moderno: A Paródia e a Política. In: A

Poética do Pós-Modernismo. Rio de Janeiro: Imago, 1991. 
HUYSSEN, Andreas. Mapeando o Pós-Moderno. In: HOLLANDA, Heloísa Buarque de. Pós-Modernismo e Política. Rio de Janeiro: Rocco, 1991, p. 15-80.

JAMESON, Frederic. A Lógica Cultural do Capitalismo Tardio. In: . PósModernismo. A Lógica Cultural do Capitalismo Tardio. São Paulo: Ática, 1996, p. 27-79 KULKA, Thomas. Kitsch + Art. Pennsylvania: The Pennsylvania State UP, 1996, p. 1100.

NAVARRO-DANIELS, Vilma. Tejiendo Nuevas Identidades: La Red Metaficcional en Todo Sobre Mi Madre, de Pedro Almodóvar. Connecticut: The University of Connecticut, 2003.

NUÑEZ, Carlinda Fragale Pate. O Imaginário Trágico de Almodóvar em Tela: Tudo Sobre Minha Mãe, Clitemnestra. In MONTEIRO, Maria Conceição \& LIMA, Tereza Marques de Oliveira (orgs.). Dialogando com Culturas: Questões de Memória e Identidade. Niterói: Vício de Leitura, 2003.

SONTAG, Susan. Notes on Camp. [Tradução nossa]. Disponível em http://interglacial.com/ sburke/pub/prose/Susan_Sontag_-_Notes_on_Camp.html. Acesso em: 20/04/2011.

VERNON, Kathleen M. Melodrama Against Itself - Pedro Almodóvar's What Have I Done to Deserve This? Columbia: Columbia UP, 2003.

\section{Title}

Pedro Almodovar and Susan Sontag - Camp Intersections

\section{Abstract}

This paper seeks to analyze, in a interdisciplinary way, the theoretic intersections between the film All About My mother, by Pedro Almodovar, and the paper Notes About the Camp, by Susan Sontag. Thus, we will criticize trying to perceive how this "sensibility" - the Camp - can be felt in some performances of this film.

\section{Keywords}

Cinema; Literature; Culture; Camp.

Recebido em 26.04.2011. Aprovado em 11.07.2011. 